\title{
Los afanes de la Teoría de la Interpretación Constitucional ${ }^{*}$
}

\author{
DANIELA ACCATINO** \\ UNIVERSIDAD AUSTRAL DE CHILE
}

Resumen: El presente trabajo nos presenta una aproximación a las tareas (afanes) de la interpretación constitucional, para esto la autora desarrolla primero, una teoría general de la interpretación jurídica para luego llegar a una teoría especial de interpretación constitucional.

La teoría general se basa principalmente en la filosofía del lenguaje, analizando los problemas que suelen darse al asignar un ámbito estrecho de interpretación y una amplitud integrando un elemento pragmático. La teoría especial de la interpretación constitucional es abordada en dos elementos, desde una reconstrucción descriptiva a una orientación normativa. Las tesis descriptivas analizadas giran en torno a la concepción dominante sobre la función de la Constitución y a lo que implica la sujeción a un Estado de Derecho en las decisiones constitucionales chilenas. Por otra parte, las tesis normativas desarrolladas son cada una críticas a las tesis descriptivas extraídas desde la jurisprudencia enunciadas anteriormente.

Abstract: The present work presents an approximation to constitutional interpretation's tasks (eagerness), for this the author develops first in first place, a constitutional interpretation's general theory of constitutional interpretation, and then arriving to a constitutional interpretation's special theory.

The general theory is supported mainly in philosophy language, analyzing the narrow interpretation conception's troubles and the amplitude when a pragmatic element is introduced.

The constitutional interpretation's special theory is boarded by two elements, from descriptive reconstructions to a normative direction.

The analyzed descriptive thesis turn around the dominant conception on Constitution's function and what implies the State of Right's subjection in Chilean constitutional's ruling.

By other side, the developed normative's thesis there are each one a critic to extracted descriptive theses from jurisprudence, previously enunciated.

Palabras Clave: Funciones de la Interpretación Constitucional, Reconstrucción Descriptiva, Orientación Normativa, Teoría Semántica.

Keywords: Constitutional Interpretation's functions, descriptive reconstruction, normative directions, semantic theory.

\footnotetext{
* Este trabajo ha sido realizado en el matco y con el financiamiento del Proyecto FONDECYT N" 1050388 "Certeza e igualdad en la tutela jurisdiccional de los derechos fundamentales", del que la autora es co--investigadora.

** Profesora del Instituto de Derecho Privado y Ciencias del Derecho de la Universidad Austral de Chile. Abogada. Licenciada en Cs. Jurídicas y Sociales y Magíster en Filosofía, Universidad de Chile. Doctora en Derecho, Universidad de Granada. E mail: daccatino@uach.cl
} 


\section{Teoría y práctica constitucional}

1. La convocatoria a esta Sesión Plenaria nos invita a discutir sobre el sentido y las ambiciones de una teoría de la interpretación constitucional. Ella nos somete -a los excéntricos cultores de la teoría- al saludable desafío de explicar qué hacemos y por qué, frente a un público en el que predominan los estudiantes de Derecho. Un auditorio que, de acuerdo a mi experiencia, tiende ser más bien ávido de práctica y escéptico respecto de la relevancia de la teoría. Debo admitir, con todo, que el nombre de este Congreso Estudiantil desmiente esa impresión. Espero que este ejercicio contribuya a confirmar que se justifica un Congreso de Derecho y "Teoría" Constitucional (y no, en cambio, a decidir cambiar su denominación en la próxima versión).

2. Tal como sugiere la convocatoria, en principio parece posible distinguir dos tareas propias de una teoría de la interpretación constitucional por su modo de hacer referencia a la práctica constitucional: para ofrecer una reconstrucción descriptiva, en un caso, y para proponer una orientación normativa a la misma, en el otro.

Antes de dilucidar en qué podrían consistir esas tareas, descriptiva y normativa, de la teoría, por qué tiene sentido emprenderlas y cuáles son sus relaciones, conviene precisar las dimensiones de la práctica jurídica a las que hacemos referencia cuando hablamos de interpretación constitucional. Pues, como ocurre con la interpretación jurídica en general, es posible hablar de interpretación constitucional en sentidos más o menos amplios y para designar actividades que se realizan en diferentes contextos y situaciones.

En sentido amplio es posible hablar de interpretación constitucional para hacer referencia a toda comprensión o atribución de significado al texto que identificamos como la constitución vigente en un cierto sistema jurídico. Cuando esa atribución tiene lugar en una situación de duda o controversia hablamos de interpretación en un sentido restringido —un sentido al que recurrimos cuando decimos, por ejemplo, que in claris non fit interpretatio. ${ }^{1}$

Por otra parte, hay diversos contextos en que la atribución de significado al texto constitucional puede tener lugar. Así, podemos notar como diversas clases de sujetos interpretan la constitución, con diversos propósitos: además de la interpretación auténtica que puede realizar el órgano constituyente, ${ }^{2}$ existen interpretaciones privadas—realizadas por abogados, juristas y ciudadanos- e interpretaciones oficiales de la constitución, realizadas con el propósito de adoptar una decisión autoritativa. La interpretación oficial puede a su vez ser realizada por una autoridad normativa, a fin de determinar el ámbito de su propia competencia, así como los procedimientos y restricciones sustantivas a las que está sujeto su ejercicio, o bien por un órgano con competencias de control o revisión constitucional, que deba pronunciarse en concreto sobre la posible infracción de algún precepto constitucional. Por supuesto que también esta clase de órgano tendrá que interpretar cuál es el alcance de sus propias competencias de control constitucional, pero la peculiaridad de su posición reside en que realiza además un juicio autoritativo sobre la constitucionalidad de los actos de otros sujetos. Me referiré a esta última forma de interpretación constitucional como interpretación operativa, para distinguirla de la interpretación oficial general. ${ }^{3}$

\footnotetext{
${ }^{1}$ Cfr. WROBLEWSKY, Jerzy, Constitución y Teoria General de La Intepretación Juridica, Madrid, Ed. Civitas, 1985, pp. 21 y ss.

${ }^{2}$ La disciplina jurídica de la interpretación constitucional auténtica presenta en Chile una anomalía. De acuerdo a lo dispuesto por el artículo 66 de la Constitución Política de la República (en adelante CPR) ella se realiza a través de normas legales, cuya producción debe sujetarse al procedimiento legislativo - con un quótum estricto de aprobación- y no en cambio al procedimiento previsto para el ejercicio de la potestad constituyente derivada.

${ }^{3}$ Se trata de una denominación ampliamente utilizada por la teoría jurídica: vid., entre otros, WROBLEWSKY, Jerzy, op. cit. (nota 1), p. 28 y BANKOWSKY, MACCORMICK y SUMMERS, "On method and methodology". En: MACCORMICK, D.N. y SUMMERS, R.S. (editores). Interpreting Statutes. A Comparative Study. Aldershot, Dartmouth-Ashgate, 1991, pp. 11-13.
} 
La variedad, antes apuntada, de situaciones en las que la interpretación de la Constitución tiene lugar, puede ser considerada también desde otra perspectiva, para distinguir entre aquellas interpretaciones que se realizan en un contexto aplicativo, esto es, con mitas a la función (explícita o implícita) de las normas constitucionales como razones justificativas de un acto o de un producto normativo, y aquellas que no. ${ }^{4} \mathrm{La}$ aplicación de una disposición constitucional presupone, en cualquier caso, su interpretación (al menos en sentido amplio); en particulat, supone abordat una tarea interpretativa túpica: la precisión del alcance de la disposición, incluyendo o excluyendo de su significado un cietto caso genérico.

Por último, y en estrecha conexión con la diversidad de contextos de la interpretación constitucional, los productos a través de los cuales se expresa la actividad interpretativa son también diversos. En algunos casos -como ocurrirá usualmente tratándose de interpretaciones oficiales no operativas - no habrá otro producto que el acto normativo cuya justificación supone un enunciado interpretativo que no se explicita. En otros contextos, en cambio, se formularán explícitamente los enunciados interpretativos que atribuyen significado a una o varias disposiciones constitucionales y se invocarán argumentos interpretativos para justificarlos.

Sin perjuicio de que la interpretación como actividad pueda ser objeto de estudios que intenten descripciones heurísticas de los procesos psíquicos en que ella consiste, el interés de una teoría de la interpretación constitucional se concentratá en sus productos lingüísticos, esto es, en la afirmación, el intercambio y el juego recíproco entre los diversos enunciados y argumentos interpretativos. Estos últimos son, por su carácter público, los que interesan como punto de partida cuando se trata de comprender o de evaluar la "interpretación jurídica" como práctica social.

3. Una teoría de la interpretación constitucional tiene que tomat en cuenta el conjunto de las atribuciones de significado al texto constitucional que antes hemos identificado.

Con todo, es usual que las teorías de la interpretación presten especial atención a la interpretación operativa. Ello se debe, por una parte, a la especial posición que ocupan algunos sujetos que realizan esa clase de interpretación, al ser competentes para decir la última palabra sobre el significado de la constitución. Eso los vuelve destinatarios predilectos de las teorías normativas de la interpretación constitucional.

Por otra parte, en sede jurisdiccional tienen lugar, típicamente, controversias acerca del significado, para las que una teoría de la interpretación tiene que poder ofrecer una explicación. Adicionalmente, dado que los tribunales que realizan esa clase de aplicación constitucional suelen estar sujetos a la exigencia institucional de fundamentar públicamente sus decisiones, en sus sentencias debería ser posible encontrar no sólo la afirmación de un cierto significado constitucional, sino también las razones que justifican la atribución de significado que realizan y que la hacen preferible respecto de otras interpretaciones rivales. Eso hace que se trate de un material que puede ser extremadamente valioso para una reconstrucción de los códigos interpretativos vigentes en una cierta cultura jurídica (en la medida que los órganos en cuestión tomen en serio las exigencias de justificación a las que están sujetos). 5

Pero la reconstrucción que ofrezca una teotía descriptiva de la interpretación tiene que tomar en cuenta también el modo en que esas interpretaciones son evaluadas en la comunidad jurídica (espe-

\footnotetext{
${ }^{4}$ Sobre este concepto de aplicación de una norma jurídica vid. GIANFORMAGGIO, L., "Modelli di Ragionamento Giuridico. Modello Deduttivo, Modello Induttivo, Modello Retorico", En: SCARPELLI, U. (editor), La Teoria Generale del Diritto. Problema $e$ Tendenze Atruali. Mîlán, Giuffrè, 1983, pp. 137 y ss. Con respecto a la distinción entre justificación de un acto y justificación de una notma, cfr. CARACCIOLO, R, Sistema Juridico, Problemas Actuales, Madtid, Centro de Estudios Constitucionales, 1988, Pp. $75-77$.

${ }^{5}$ Cfr. BANKOWSKY, Z, MACCORMICK N., y SUMMERS, R. S., op. cit. (nota 2), pp. $13-16$.
} 
cialmente, pero no exclusivamente, en la comunidad de juristas). ${ }^{6}$ De lo contrario no sería posible dar cuenta cabalmente del carácter normativo de las prácticas de interpretación jurídica, ni de una distinción conceptual que resulta crucial para representar el punto de vista de los partícipes y que distingue entre el carâcter definitivo y el carácter infalible de una cierta atribución oficial de significado. ${ }^{7}$

Interpretación constitucional y teorías generales de la interpretación jurídica: la especificidad del significado jurídico

4. La eventual especialidad de las tesis teconstructivas y de las tesis normativas de una teoría de la interpretación constitucional dependerá de las peculiaridades que las prácticas de atribución de significado al texto constitucional presenten o deban presentar con respecto a la atribución de significado a otras clases de textos normativos, como, por ejemplo, la legislación. Una teoría "especial" de la interpretación constitucional —como también una teoría especial de la interpretación de la ley- presupone, sin embargo, el apoyo en una teoría "general" de la interpretación jurídica, que precise en qué consiste atribuir significado a un texto jurídico. En relación a esta cuestión previa, me parece relevante considerar la disyuntiva entre dos concepciones generales acerca del significado jurídico, de las que se siguen, como intentaré mostrar enseguida, diferentes formas de entender y de deslindar las tareas de una teoría descriptiva y de una teoría normativa de la interpretación constitucional.

La disyuntiva en cuestión es la que contrapone a las teorías que niegan y a las que afirman la especificidad de la interpretación en el ámbito jurídico con respecto a otras prácticas interpretativas, como, por ejemplo, la interpretación del lenguaje ordinario. ${ }^{8}$ En particular me interesa considerar cómo se distribuyen entre estos dos polos algunas teorías contemporáneas de la interpretación jurídica que se apoyan en diversas herramientas desarroiladas por la filosofía del lenguaje y que, a pesar de sus diferencias, comparten una aproximación convencionalista al significado. ${ }^{9}$

5. La primera concepción mira la interpretación de textos jurídicos como una práctica sustancialmente semejante a la comunicación lingüística general, que pone en juego las competencias lingüísticas de los intérpretes y que no presenta dificultades específicas, diversas a las que suscita la interpre-

\footnotetext{
¿Vid. HÄBERLE, Peter, "La Sociedad Abierta de Intérpretes Constitucionales". En: Retos Actuales del Estado Constitucional, Oñat, IVAP, 1996.

${ }^{7}$ Como se sabe, se trata de una distinción que, teferida en términos generales a la decisión judicial, fue subrayada por HART, H.L.A, en El Concepto de Derecbo, Buenos Aires, Abeledo-Perrot, 1963, pp. 176 y ss. La admisión de la normatividad del significado jurídico no implica techazar a priori la plausibilidad de una teoría escéptica de la interpretación legal o constitucional. Sólo supone reconocer que esa práctica comprende la crítica interna de la corrección o incorrección de ciertas atribuciones de significado. Es posible que, reconociendo este punto, concluyamos luego que una cierta comunidad jurídica carece de convenciones interpretativas estables y de criterios públicos de evaluación de las atribuciones de significado, de modo que en ella los juicios de corrección o incorrección no expresen sino las preferencias personales del intérprete. Volveremos sobre csto, así como sobre la cuestión de la posibilidad de una teoría "descriptiva" de una práctica "normativa", más adelante (infra \$12).

${ }^{8} \mathrm{La}$ distinción que se propone coincide sustancialmente con la que CHIASSONI, Pierluigi delinea entre las concepciones semánticas y concepciones pragmáticas de la interpretación jurídica, en "Codici Interpretativi. Progetto di Voce per un Vademecum Giuridico", En: COMARDUCCI, P. y GUASTINI, R. (editores.), Analisi e Diritto 2002-2003. Turin, Giappichelli, 2003 , pp. $60-63$. Agregaré, sin embargo, algunos puntos de comparación que me parecen significativos y extraeré algunas conclusiones de las que el citado autor no se ocupa.

${ }^{9}$ Esto implica dejar fuera del análisis las teorías de la interpretación jurídica que se apoyan en una teoría realista del significado, que sostenga - como lo hace Michael MOORE, en "A Natural Law Theory of Interpretation", Southem California Law Review, $N^{\circ} 58,1985$, p. 338 - que encontrar el significado de una palabra no consiste en "hallar algunas convenciones estipuladas anteriormente" sino en "descubrit cómo el mundo está constituido". Para una crítica, que no es posible emprender en esta sede, a esta teoría y su aplicabilidad en el ámbito de la interpretación jutídica remito al lector a BIX, B., Lam, I anguage and Legal Determinagy, Oxford, Clarendon Press, 1993, pp. 162 y ss. y a MORESO, J. La Indeterminación del Derecbo y la Interpretación de la Constituaión., Madrid, Centro de Estudios Constitucionales, 1997, pp.200 y ss.
} 
tación del lenguaje ordinario. Esta concepción ha sido sostenida por varios representantes connotados de la teoría jurídica positivista, como Herbert HART, Eugenio BULYGIN Y José Juan MORESO. ${ }^{10}$

Apoyándose en la noción de significado como función de las modalidades de uso de una expresión --bajo la influencia, en el caso del positivismo hartiano, de la elaboración que de ella ofrece WITTGENSTEIN en sus Imvestigaciones Filosóficas_-11, esta primera concepción de la interpretación jutídica, considera que también las expresiones utilizadas en documentos normativos poseen los significados que resultan de las reglas semánticas que registran sus modalidades de uso - de uso por los juristas, si se trata de un término técnico; de su uso general u ordinario, de lo contrario. De ahí que podamos designarla como concepción semántica de la interpretación jurídica. ${ }^{12}$

Sobre esta base, la concepción en cuestión ofrece una caracterización de las prácticas de interpretación jurídica centrada en la distinción entre dos clases de situaciones. En una primera clase de situaciones, el intérprete puede reconocer el significado usual de las expresiones jurídicas y constatar que éste comprende (o excluye) el caso (genérico o particular) que debe resolver. En esas circunstancias, cualquier otra atribución de significado al texto normativo y cualquier otra solución al caso suponiendo que no hay otras normas jurídicas relevantes - resultará jurídicamente incorrecta.

En una segunda clase de situaciones el intérprete se enfrenta a dudas o controversias sobre el significado atribuible a una expresión jurídica. Estas dificultades — que dan lugar a los casos difíciles y a la interpretación en sentido estricto- son, de acuerdo a esta teoría de la interpretación jurídica, análogas a las que pueden surgir en la interpretación de expresiones de los lenguajes naturales. Su origen se encuentra en la ambigüedad y sobre todo en la vaguedad o textura abierta de los términos genéricos. Cuando estas dificultades lingüísticas tienen lugar, los partícipes no pueden reconocer un significado unívoco a las expresiones jurídicas, sino que lo estipulan sobre la base de criterios diversos a los que proporcionan las reglas semánticas. En estos casos la decisión que se adopte sobre la base de esa estipulación de significado resulta desde el punto de vista del derecho — suponiendo que no hay otras normas jurídicas relevantes- discrecional. En este espacio de discrecionalidad pueden jugar un limitado papel orientador y justificativo - al que los autores en cuestión no suelen, con todo, prestar demasiada atención- ${ }^{13}$ los tradicionales cánones de interpretación —sistemático, teleológico, genético, etc.

6. Si aceptáramos esta primera concepción del significado jurídico, el sentido de una teoría especifica de la interpretación constitucional resultaría bastante estrecho. Pues si se asume como una cuestión conceptual que el significado de una disposición jurídica resulta determinado (o indeterminado en su caso) por las reglas semánticas que rigen su uso técnico o general, no parece haber espacio ni para la reconstrucción ni para la prescripción de otras directivas hermenéuticas en el ámbito de la interpretación constitucional. A lo sumo, una teoría de la interpretación constitucional podría ofrecer un registro de los problemas lingüísticos que se presentan con especial frecuencia o intensidad en el caso de la interpretación de la Constitución. Así, por ejemplo, un análisis de este tipo podtía poner de relieve la notoria presencia en la parte dogmática de la Constitución de "conceptos esencialmente

\footnotetext{
${ }^{10}$ Cfr. pot ejemplo, HART, H. op. cit (nota 7), pp. 155 y ss.; ALCHOURRÓN, C. y BULYGIN, E. "Los Límites de la Lógica y el Razonamiento Jurídico", En: IDS., Análisis Lógico y Derecho. Madrid, Centro de Estudios Constitucionales, 1991, pp. 303-328; BULGYN, E. "Cognition and Interpretation in Law", En: GIANFORMAGGIO, L. y PAULSON, S. Cognition and Interpretation in Law. Turín. Giappichelli, 1995, pp. 11-35; MORESO, J.J., op. cit.. (nota 9), pp. 183 y ss.

11 Vid. WITTGENSTEIN, Investigaciones filosíficas. Barcelona, Crítica, 1988, especialmente $\$ \S 138,139,190,191$ y 198 . Sobre el recurso la conexión entre la filosofía del lenguaje del último WITTGENSTEIN y la teoria juridica del positivismo hattiano, vid. ENDICOTT, Timothy. "Law and language", En; COLEMAN, J. y SHAPIRO, S. (editores.). The Oxford Handbook of Jurisprudente and Philosophy of Law. Oxford, Oxford U. Press, 2004, pp. 946 y 949.

${ }^{12}$ Vid. supra nota 8.

${ }^{13}$ Vid., por ejemplo, HART, H. op. cit. (nota 7), p. 158.
} 
controvertidos" y sus consecuencias desde la perspectiva del grado de discrecionalidad con que contarían los intérpretes constitucionales. ${ }^{14}$

7. Sin embargo, la reconstrucción que la teoría semántica ofrece de las prácticas de interpretación jurídica — así como también, por consiguiente, la reducida imagen de las tareas de una teoría de la interpretación constitucional que de ella se sigue - no resulta aceptable ni desde la perspectiva de la experiencia jurídica ni desde la perspectiva de diversas aportaciones de la filosofía del lenguaje que destacan la relevancia de la dimensión pragmática de los discursos. ${ }^{15}$

Desde la perspectiva de la experiencia jurídica, la debilidad fundamental de la concepción semántica de la interpretación jurídica consiste en asumir respecto de toda práctica jurídica, como si se tratara de una cuestión conceptual, la primacía, en todo caso jurídico, del significado literal (entendido como significado usual, ya sea técnico o general) de los documentos normativos. Hay diversos aspectos de las prácticas jurídicas de las sociedades modernas que desmienten esa suposición y revelan la incapacidad de la teoría semántica de dar cuenta satisfactoriamente del punto de vista de quienes participan en ellas.

Así ocurre con las prácticas, nada inusuales, de interpretación restrictiva o extensiva de determinadas disposiciones legales o constitucionales, fundadas en consideraciones relativas al propósito o el fin subyacente a la norma. ${ }^{16} \mathrm{O}$, en general, con la prioridad asignada, bajo ciertas circunstancias, al significado justificado sobre la base de otros argumentos interpretativos — como, por ejemplo, alguna forma de argumento sistemático- - frente al significado literal, en casos en que éste no resultaba, desde el punto de vista semántico, ni ambiguo ni vago. Esto es lo que sucedió, como se recordará, en un célebre caso de nuestra práctica constitucional reciente, cuando en 1985 el Tribunal Constitucional declaró inconstitucional la ley orgánica constitucional sobre Tribunal Calificador de Elecciones y requirió su entrada en vigencia con anterioridad al plebiscito de 1988, descartando la interpretación que resultaba del tenor literal de la disposición 11 transitoria, según la cual el antiguo artículo 84 de la Constitución, relativo al Tribunal Calificador de Elecciones, sólo debía comenzar a regir con ocasión de la primera elección de senadores y diputados. ${ }^{17}$

No obstante la convergencia casi unánime de la doctrina chilena en juzgar como correcta. conforme a derecho esa decisión, la teoría semántica de la interpretación llevaría a concluir que se trata en realidad de una decisión incorrecta, contraria a derecho. Sin embargo, si el sentido de esa teoría es describir la práctica social en que consiste la interpretación del derecho, entonces resulta difícil comprender cuál sería esa realidad que hace que los partícipes de la práctica jurídica se equivoquen. Parece más bien que una teoría que no es "capaz de ponerse en el lugar del partícipe", ni logra representar adecuadamente "qué entraña el punto de vista interno", es, simplemente, una mala teoría descriptiva de una práctica social. ${ }^{18}$ Por supuesto que eso no cierra la posibilidad de discutir si resulta deseable, a la luz de ciertos fines o valores, que una práctica jurídica otorgue preeminencia en todo caso jurídico al significado literal de los documentos normativos: esa discusión nos saca, sin embargo, del terreno de

\footnotetext{
${ }^{14}$ Un análisis de este tipo puede encontrarse en MORESO, J.J., "Algunas consideraciones sobre la interpretación constitucional", Doxa No 23,2000

15 En el mismo sentido cfr. CHIASSONI, op. cit. (nota 8), pp. 61 y 62. Vid. también, del mismo autor, "Interpretative Games: Statutory Construction through Gricean Eyes", En: COMANDUCCI, P. y GUASTINI, R. (editores), Analisi e Diritto 1999. Tutín, Giappichelli, 1999 , pp. 82 y ss.

${ }^{16}$ La interpretación restrictiva de una disposición jurídica designa un tipo de práctica que corresponde a lo que la teoria jurídica actual llama derrotabilidad (defeasibility) de las reglas jurídicas. El análisis de este aspecto de las prácticas jurídicas ha suscitado, en los últimos años, una viva polémica sobte sus implicaciones respecto de la plausibilidad de las tesis centrales del positivismo jurídico. Sobre ella vid., por ejemplo, BAYÓN, J. C. "Dertotabilidad, Indeterminación del Derecho y Positivismo Jurídico", en Isonomía, No 13, 2000, y ATRIA, F. On Law and Legal Reasoning. Oxford, Hart Publishing, 2001, especialmente pp. $161 \mathrm{y}$ ss.

${ }^{17}$ Cfr. Sentencia del Tribunal Constitucional Rol No 33, de 20 de agosto de 1985.

${ }_{18}$ Las expresiones entrecomilladas son empleadas por HART para caracterizar la tarea de una teoria descriptiva del detecho en su "Postcript" a El Concepto de Derecho publicado póstumamente: The Concept of law. Oxford, Oxford U. Press, 1994, p. 242.
} 
la pregunta sobre cómo se atribuye significado a las disposiciones jurídicas —que es la pregunta que las teorías semánticas de la interpretación jurídica pretenden responder-, para llevarnos al ámbito de una teoría normativa de la interpretación jurídica. ${ }^{19}$

8. Las deficiencias antes indicadas pueden explicarse por la escasa atención que la concepción del significado jurídico que hemos analizado presta a la dimensión pragmática de los discursos. ${ }^{20}$ En este sentido, ella resulta insatisfactoria también desde el punto de vista de diversas contribuciones recientes de la filosofía del lenguaje que destacan la relevancia de los factores pragmáticos, presentes en la ocasión específica de uso del lenguaje, en la determinación del significado de una enunciación.

El propio WITTGENSTEIN, por ejemplo, quien, según hemos visto, ${ }^{21}$ ejerció una considerable influencia, a través de sus Investigaciones Filosóficas, en el positivismo hartiano, puso de relieve el carácter contextual del significado y su dependencia respecto del concreto "juego de lenguaje" en el que una enunciación es proferida. ${ }^{22}$ HART no parece haber llegado a vislumbrar, sin embargo, todas las consecuencias que esa dependencia contextual podía implicar respecto del significado jurídico; entre ellas, por ejemplo, la posibilidad que en el marco de una cierta práctica jurídica el uso de una expresión en una disposición jurídica pudiera requerir, en virtud de una convención específica, que se tome en cuenta y se intente dar efecto al propósito o fin subyacente a la norma. ${ }^{23}$

La posibilidad de convenciones interpretativas específicas relevantes en el (o, más específicamente aún, en algún) contexto de uso jurídico de las palabras puede encontrar apoyo también en las ideas de Paul H. GRICE y su análisis de los presupuestos de la comunicación. ${ }^{24}$ Pues así como una conversación ordinaria que tiene el propósito de intercambiar u obtener información puede ser entendida, según sugiere GRICE, como una transacción cooperativa que implica la sujeción de los participantes a una serie de máximas, las que serán presupuestas en la atribución de significado a sus discursos, otras clases de comunicaciones, y sus correspondientes juegos interpretativos, pueden estar sujetos a una serie diferente de máximas. ${ }^{25}$

9. La importancia de las consideraciones pragmáticas es adecuadamente calibrada por la segunda concepción, que podemos por eso designar como pragmática, de la interpretación jurídica. ${ }^{26}$ Esta

${ }^{19}$ La teoria semántica de la intetpretación juridica cierra, por lo demás, el espacio conceptual pata esa clase de discusión (vid. supra \$ 6). Para que esa discusión tenga sentido es preciso admitir primero que es conceptualmente posible una forma de atribución de significado a los textos jurídicos que no resulta determinada (sólo) por las reglas semánticas que rigen el uso de los términos a través de los cuales ellos se expresan.

${ }_{20}$ Con respecto a este defecto cabe hacer - como sugiere CHIASSONI, op. cit.. (nota 15), pp. 80-82-una distinción entre dos versiones de la concepción de la interpretación que hemos descrito: una centrada en el significado de las palabras ("wordmeaning theory") — sostenida, por ejemplo, por BULYGIN - y otra que atiende en cambio al. significado de las oraciones ("sentence - meaning theory") - representada, por ejemplo, por MORESO. Esta última, al considerar que las unidades básicas de las ttansacciones lingüísticas son las oraciones — y no las palabras -, tomatía en cuenta dos dimensiones del discurso — la sintáctica y la pragmática- que la primera descuidaría. Sin embargo, puesto que la segunda teoría sostiene que atribuir significado a las oraciones jurídicas consiste en precisar el significado de las oraciones declarativas o descriptivas que informan acerca de la conducta requerida o permitida ( $O$, en otras palabras, de los enunciados declarativos que muestran en qué condiciones el enunciado jurídico es cumplido, o eficaz: cfr. MORESO, op. cit. nota 9, pp. 24ss.), su enfoque pragmático se encontratia "semánticamente cargado". La función de las oraciones no juega, en definitiva, ningún rol en la determinación de su "contenido proposicional"; ; éste se identifica con el significado de las oraciones descriptivas correspondientes, determinado por las reglas semánticas respectivas.

21 Vid. supra nota 11.

${ }^{22}$ Cfr. WITTGENSTEIN, op. cit.. (nota 11), especialmente $\$ S 49,525,8$ y 23

${ }_{23}$ Una aplicación en esta línea del principio wittgensteniano del contexto - y una crítica semejante a su patcial olvido por HART_- puede verse en ENDICOTT, T., op. cit.. (nota 11), pp. 957-958.

${ }^{24}$ Cfr. GRICE. Studies in the way of words. Cambridge, Mass, Harvard U. Press, 1989.

${ }^{25}$ Es la línea de argumentación que desarrolla CHIASSONI, op. cit.. (nota 15), pp. 93 y ss.

26 Vid. sitpra nota 8 . Esta sintonía de la teoría pragmática con una aproximación filosófica general al significado que destaca plausiblemente su variabilidad de acuerdo a la clase de comunicación involucrada es, por otra parte, una razón que la hace preferible con respecto a otra posible respuesta frente a las debilidades de la teoría semántica de la intetpretación jurídica explorada, por ejemplo, por ATRIA, F. op. cit.. (nota 16), pp. 87 y ss.-, que consiste en distinguir entre el significado de una 
perspectiva asume la peculiaridad de los juegos de interpretación jurídica y considera que el significado de un documento normativo es función de consideraciones definidas por directivas hermenéuticas, que pueden no ser exclusivamente o prioritariamente consideraciones lingǘsticas, establecidas por reglas semánticas. ${ }^{27}$ Pueden ser también consideraciones relativas a las intenciones del autor, considetaciones que remiten a las opiniones autorizadas de expertos, consideraciones teleológicas o finalistas, consideraciones de moral critica u otras. La reconstrucción del o de los códigos interpretativos que tijan la selección y el uso de las consideraciones de las que depende la atribución de significado en una cierta práctica jurídica constituirá la tarea ptopia de una teoría descriptiva de la interpretación jurídi$\mathrm{Ca}^{28}$

Cabe advertir que la adopción de una perspectiva pragmática frente al significado jurídico no supone prejuzgar cual sea el resultado de esa empresa, ni asumir necesariamente una posición escéptica, que dé la razón a Humpty Dumpty y afirme que en el juego de la interpretación jurídica lo relevante en relación al significado de las palabras sea - como le decía el curioso personaje a una sorptendida Alicia— "quién es el que manda". ${ }^{29}$

El dilema que propone Humpty Dumpty, que no es otro que el de la posibilidad de la sujeción, también de las autoridades y particularmente de los jueces, a derecho, se resolverá —si es que se resuelve - en el nivel de las convenciones interpretativas. Puede ocurtir que la reconstrucción de una cierta práctica interpretativa sugiera que Humpty Dumpty tiene razón, pues no resulte posible reconocer la convergencia en ciertos criterios públicos de evaluación de la corrección de la atribución de significado a los textos normativos. Pero también es posible que ocurra lo contratio. Los pronósticos de quienes comparten una perspectiva pragmática apuntan en ambos sentidos: algunos análisis son más optimistas y proponen la imagen de la interpretación jurídica como un juego sujeto a convenciones relativamente estables que fijan condiciones a la justificabilidad de una tesis interpretativa, ${ }^{30}$ mientras otros, más pesimistas, miran las prácticas de interptetación jurídica como un juego tendencialmente anárquico que deja siempre espacio a la elección particularista y estratégica por el intérptete de uno entre varios códigos interpretativos alternativos. ${ }^{31}$

10. La concepción pragmática de la interpretación jurídica no impone restricciones conceptuales injustificadas y ofrece, en cambio, un matco apropiado para el desarrollo de teorías especiales de la interpretación jurídica, relativas a los diversos ámbitos de una práctica jurídica. Por otra parte, al poner

orada, por ejemplo, por ATRIA, F. op. cit.. (nota 16), pp. 87 y ss.--, que consiste en distinguir entre el significado de una norma juridica y las otras posibles consideraciones relevantes para determinar sus efectos prácticos. Una segunda desventaja de esta alternativa -que es puesta de relieve también por GREENWALT. "Constitutional and Statutory interpretation", En: COLEMAN, J. y SHAPIRO, S. (editores), op. cit. (nota 11), p. 274 - tiene que ver con su lejanía con respecto a ios usos lingüísticos de abogados, juristas y jueces, quienes se refieren al significado de una noma juridica como aquello que determina su aplicación (o no) a un cietto caso.

27 Además de CHIASSONI, op. cit.. (nota 8), otros autores cuyos planteamientos pueden ser, en mi opinión, adscritos a esta concepción de la intexpretación juridica son AARNIO, A. Lo Racional como Razonable. Madrid, Centro de Estudios Constitucionales, 1987, pp. 141 y ss.; ALEXY, R. Teoria de la Argumentación Juridica. Madrid, Centro de Estudios Constitucionales, 1997, pp. 223 y ss.; BAYÓN, J.C. Derecho, Convencionalismo y Controversia, En: NAVARRO, P.E. y REDONDO, C. (editores.), La Relevancia del Derecbo. Barcelona, Gedisa, 2002, pp. 62 63; GREENAWALT, K. , op. cit.. (nota 26), pp. 273-274; GUASTINI, R. "Due Esercizi di Non-cognitivismo", En: COMANDUCCI, P. y GUASTINI, R. (editores.), Anatisi e Diritto 1999. Turín, Giappichell, 1999, p. 279; PECZENIK A. On Law and Reason. Dordrecht, Kluwer, 1989, pp.372 y ss.

${ }_{28}$ Un ejercicio notable de reconstrucción de las prácticas interpretativas de la ley en varios sistemas jurídicos contemporáneos puede verse en MACCORMICK, D. N. y SUMMERS, R S. (editores.), op. cit. (nota 3).

${ }^{29}$ Cfr. CARROLL, L. Tthroub the looking-glass. Londres, The New English Libraty, 1960, p. 186: " - Pero gloria no significa un argumento apabullante - objetó Alicia. - Cuando yo uso una palabra - rebatió Humpty Dumpty con tono altivo, -- ella significa precisamente aquello que quiero que signifique... ni más ni menos. — La cuestión es, — dijo Alicia, - si puedes hacer que las palabtas signifiquen tantas cosas diferentes - - - La cuestión es, - respondió Humpty Dumpty, -- quien es el que manda... eso es todo - "."

${ }^{30} \mathrm{Cfr}$. AARNIO, op. cit.. (nota 27); ALEXY, op. cit.. (nota 27) y PECZENIK, op. cit.. (nota 27).

${ }^{31} \mathrm{Cfr}$. CHIASSONI, op. cit. (nota 8) y GUASTINI, op. ait. (nota 27). 
de relieve el carácter constitutivo de los códigos interpretativos y mostrar como instituyen el juego de atribuir significado a los textos jurídicos, esa concepción ilumina el sentido práctico de esas empresas teóricas.

Una teoría descriptiva de la interpretación jutídica, liberada del punto fijo y necesario de apoyo que la concepción semántica del significado jurídico veía en las reglas semánticas, nos presentará una reconstrucción de la forma que contingentemente le hemos dado a nuestros juegos de interpretación jurídica. Podremos, por tanto, ver en ese espejo la imagen de lo que somos, sabiendo, al mismo tiempo, que podríamos ser de otro modo.

El estímulo que esa imagen puede significar para avanzar hacia una práctica interpretativa más reflexiva, resultará completado, por otra parte, por los esfuerzos de una teoría normativa de la interpretación jurídica, que proporcione una evaluación crítica de esa imagen a la luz de ciertos fines o valores que puedan aspirar a ser compartidos por quienes participamos de la misma práctica.

Los afanes de una teoría descriptiva y una teoría normativa de la interpretación constitucional

11. En el ámbito específico de la práctica constitucional, los desafíos abiertos a una teoría descriptiva y a una teoría normativa de la interpretación tesultan particularmente interesantes.

La aproximación pragmática a la interpretación jurídica permite comprender, en ese terreno, como muchos rasgos distintivos de las prácticas constitucionales de la segunda posguerra, a las que se suele aludir cuando se habla de constitucionalización de los sistemas jurídicos, son rasgos contingentes que no se siguen de alguna cualidad intrínseca del texto constitucional, sino de las directivas hermenéuticas que han ido cobrando forma, a la luz cierta forma de comprender las funciones de una constitución y una cierta forma de comprender que significa la sujeción a un Estado constitucional de derecho. Pues si bien la impregnación de la práctica jurídica por las normas constitucionales, que es distintiva de los procesos de constitucionalización, supone necesariamente dos condiciones estructurales — la tigidez constitucional y la garantía jutisdiccional de la constitución-, las demás condiciones que los caracterizan no consisten sino en la generalización de ciertas formas de interpretar la constitución: desde la interpretación de las disposiciones constitucionales que declaran derechos como expresivas de normas jurídicas genuinas, susceptibles de producir efectos jurídicos inmediatos, hasta su interpretación extensiva, que extrae de ellas normas implícitas capaces de cubrir todos los aspectos de la vida política y social, y su comprensión como normas aplicables en las relaciones entre sujetos privados. ${ }^{32}$

Entre las tareas reconstructivas de una teotía descriptiva de la interpretación constitucional, adquiere especial relevancia la de desentrañar los presupuestos subyacentes a las directivas hermenéuticas generalmente aceptadas en una práctica constitucional, relativos tanto a la concepción de la función de la constitución que implícitamente es asumida, como al modo de concebir la vida en común bajo un Estado de derecho. Creo que ese tipo de análisis puede resultat particularmente iluminador tanto pata la comprensión como para la evaluación crítica de nuestras ptácticas constitucionales. Esta última es la tarea propia de una teoría normativa de la interpretación constitucional, que no debiera, por tanto, limitarse a defender aisladamente las directivas hermenéuticas que considera correctas, sino que debie-

32 Cfr. GUASTTNI, R. "Ia 'Constitucionalización' del Ordenamiento Jurídico: el Caso Italiano". En: ID, Estudios de Teoría Constitucional. México DF, Fontamara, 2001, Pp. 154 y ss., donde antes de explotar las circunstancias de la constitucionalización del ordenamiento italiano, se realiza un análisis general de las condiciones de constitucionalización de los sistemas jurídicos. Sobre la vigencia de estas condiciones en la práctica jurídica chilena, pueden verse los estudios contenidos en FERRADA, J.C. (coordinador), La Constitucionalización del Derecho Chileno. Santiago de Chile, Editorial Jurídica — Universidad Austral de Chile, 2003. 
ra ser capaz de articularlas en torno a una concepción normativa de la constitución y de lo que significa vivir bajo un Estado constitucional de derecho.

En las próximas secciones de este trabajo intentaré ilustrar la forma que podría asumir esa clase de análisis, bosquejando algunas tesis reconstructivas y normativas relativas a la práctica constitucional chilena.

12. Antes de esbozar esas tesis, hay una última cuestión metodológica que no conviene dejar en el tintero. Se trata de la pregunta, recogida en la convocatoria, por la posible autonomía de las tareas descriptivas y normativas de una teoría de la interpretación constitucional o la eventual "contaminación" valorativa de las reconstrucciones descriptivas.

No es posible abordar en esta sede las dificultades generales a las que está expuesta la pretensión de neutralidad asociada a la empresa de ofrecer una reconstrucción descriptiva de una cierta präctica social y que la filosofía ha considerado largamente. Asumiré que es posible emprender, desde lo que MACCORMICK llama "un punto de vista cognitivamente interno", una descripción de la práctica jurídica que intente ser fiel a los materiales que pretende reconstruir y sobre la que sea posible discutir con sentido, diferenciando esa discusión de una que se refiera a la aprobación o desaprobación de esas prácticas. ${ }^{33}$

Con todo, esa diferencia dista de ser siempre nítida y en el terreno específico de las teorías de la interpretación jurídica hay algunos factores que facilitan la confusión y la conexión entre tesis descriptivas y normativas.

Un estímulo a la confusión reside en las posibles incertidumbres de la propia práctica que, sumadas al inevitable carácter fragmentario de los datos disponibles, pueden favorecer que su selección e interpretación se apoye, más o menos subrepticiamente, en consideraciones sobre lo que debiera ser una práctica interpretativa consolidada. Posiblemente algo así ocurre en el caso de la teoría de la interpretación constitucional sostenida por R. DWORKIN, en cuanto intenta presentar su tesis de la "lectura moral" de la Constitución como la que mejor representa la "estructura profunda" del razonamiento constitucional de los jueces norteamericanos, no obstante las diferencias e inconsistencias que puedan percibirse a primera vista, en el nivel superficial de los discursos justificativos, ${ }^{34}$ La tentación de recurrit a esta clase de estrategia resulta potenciada, como sugiere GREENAWALT, por la fuerza normativa que la defensa del mantenimiento de una práctica encuentra en el argumento de la protección de la confianza y las expectativas constituidas bajo su alero. ${ }^{35}$

Una segunda forma de entrelazamiento entre descripciones y valoraciones, es la que tiene lugar cuando se invoca un rasgo distintivo y fundamental de la práctica como argumento para la crítica de algún aspecto específico de la misma con el que resulta incoherente. Un argumento de ese tipo podría, por ejemplo, sostener que la justicia formal es un valor que los partícipes de una cierta práctica aceptan como definitorio y orientador de la misma y que, por consiguiente, debiera regir en ella una directiva hermenéutica que diera prioridad prima facie a la interpretación sostenida por el mismo órgano jurisdiccional en casos anteriores sustancialmente semejantes. Esta clase de conexión entre argumentos descriptivos y normativos, que se expresa en la posibilidad de una crítica interna a la propia prácrica, da

\footnotetext{
${ }^{33}$ Cfr. MACCORMICK, D. N. Legal Reasoning and Legal Theory. Oxford, Oxford U. Press, 1997, p. 292. Una defensa de esta posibilidad, como preludio a un trabajo que ofrece un notable ejemplo de esa tarea de "reconstrucción tacional", puede verse en BANKOWSKI, Z, MACCORMICK, D. N., SUMMERS, R.S. y WROBLEWSKI, J. "On Method and Methodology". En: MACCORMICK, D.N. y SUMMERS, R.S., op. cit. (nota 3), pp. 18--24.

${ }^{34}$ Cfr.. DWORKIN, R. Freedon's law. The Moral Reading of the Amzerican Constitution. Cambridge, Mass, Harvard U. Press, 1996, pp. 3 y 4. Existe una versión en castellano del primer capítulo, "La lectura moral y la premisa mayoritaria", en HONGJU, H. y SLYE, R C. (compiladotes.), Democracia Deliberativa y Derechos Humanos. Barcelona, Gedisa, 2004.

${ }^{35}$ GREENAWAIT, K, op. cit.. (nota 26), p. 271. De ahí, posiblemente, el esfuerzo de DwORKIN en mostrar que "la lectura motal no es una práctica tevolucionatia": op. cit.. (nota 34), p. 3.
} 
cuenta del carácter normativo de las prácticas de interpretación jurídica así como de la posible complejidad y diversidad de niveles entre las directivas constitutivas de ese juego. ${ }^{36}$

\section{Dos tesis descriptivas sobre las prácticas de interpretación constitucional en Chile}

13. El propósito de las dos últimas partes de este trabajo es ilustrar, a través de algunos ejemplos referidos a la práctica constitucional chilena, los afanes propios de una teoría de la interpretación constitucional. En particular, me interesa mostrar el potencial tanto explicativo como crítico que tiene la conexión de la descripción que se ofrezca de las prácticas interpretativas, así como su evaluación, con una cierta concepción de la función de la constitución y una concepción del Estado de derecho. Las tesis que a continuación se exponen constituyen tan sólo un bosquejo preliminar de esa clase de análisis con respecto a las prácticas de interpretación constitucional en Chile.

14. La empresa de intentar una reconstrucción descriptiva de nuestras prácticas de interpretación constitucional se enfrenta con la dificultad que resulta de la pobreza argumentativa que exhiben muchas sentencias constitucionales, las que suelen contener numerosas afirmaciones categóricas relativas a la evidencia de una cierta solución y pocos esfuerzos por establecer un nexo entre el concepto constitucional invocado y la decisión, a través de la articulación justificada de sus condiciones de aplicación. ${ }^{37}$ Tampoco contamos todavía con una dogmática constitucional suficientemente diferenciada a la que dirigit, en subsidio, la atención. Si sumamos a eso la escasa consideración que tanto nuestros Tribunales superiores como el Tribunal Constitucional prestan a sus propios precedentes, entonces se vuelve tentador llegar a conclusiones más bien bumpty-dumptianas sobre nuestra práctica constitucional y sostener que en ella las disposiciones constitucionales significan, en cada caso, lo que los intérpretes (los que mandan, por cierto) quieren que signifiquen.

Sin embargo, hay ciertos aspectos en los que nuestra práctica constitucional se presenta relativamente estable y a partir de los cuales es posible esbozar dos hipótesis reconstructivas en torno a la concepción dominante sobre la función de la Constitución y sobre el sentido de la sujeción a un Estado de derecho.

\footnotetext{
${ }^{36}$ Esta perspectiva coincide con lo que A. AARNIO caracterizando la metodología de su propia propuesta teórica, designa como "enfoque débilmente normativo". Esta aproximación encuentra su punto de partida en la "ideología jurídica nórdica dominante", "construida sobre la expectativa de que los problemas jurídicos no son decididos arbitratia o casualmente, sino a través de la consideración racional que conduce a una conclusión aceptable", de modo que la teoría comprende entonces la dilucidación de qué se requiere para que la justificación de la interpretación pueda satisfacer las condiciones de racionalidad y aceptabilidad, en cuanto "partes esenciales de la actual cultura jurídica en las sociedades nórdicas" (cfr. AARNIO, A. op. cit.. nota 27, p. 58). Un enfoque semejante parece informar la teoria de la argumentación jurídica delineada por ALEXY, R., en cuanto encuentra su punto de partida en la "pretensión de corrección" que distingue, a su juicio, los discursos jurídicos. Que las discusiones jurídicas tengan lugar bajo la pretensión de corrección implica que ellas tienen como referencia "condiciones ideales" que es tarea de la teoría intentar teconstruit, tespondiendo a la pregunta por "qué significa decidir racionalmente en el marco de un ordenamiento jurídico válido" (cfr. ALEXY, R., op. cit. nota 27, pp. 206-213). Como decía antes, estos enfoque teóricos, que combinan descripción y prescripción en sentido débil, son perfectamente válidos (dando por supuesto que los supuestos distintivos de las prácticas que asumen como puntos de partida lo son efectivamente); sin embargo, en cuanto omiten dar cuenta de los aspectos en que las prácticas que analizan se apartan de los presupuestos normativos que les atribuyen, corren el tiesgo de ofrecer una imagen mistificada y legitimadora de ellas: cfr. las críticas en este sentido de TUORI, K., "Ética Discursiva y Legitimidad del Derecho", en Doxa, No 5, 1988, p. 65.

${ }^{37}$ Este es un rasgo de nuestra práctica que ha sido identificado como un aspecto de la tendencia vulgarizadora a que habría conducido en Chile la constitucionalización del derecho: cfr. ALDUNATE, E. "La Protección al Acecho: las Consecuencias del Abandono de las Reglas de Interpretación Constitucional en el Ámbito del Recurso de Protección", en Revista de Derecho de la U. Católica de Valparaíso, No XX, 1999, Pp. 234 y 235; A'TRIA, F. “La Hora del Derecho: los 'Derechos Humanos' entre la Política y el Derecho", en Estudios Públicos, No 91, invierno 2003, pp. $61-65$ y CORREA, R. "Vulgarización por Constitucionalización", en Revista Derecho y Humanidades, No 10, 2004.
} 
15. El primero consiste en la centralidad que se reconoce tanto en la práctica judicial como en la argumentación doctrinal, en los casos en que se exhibe algún celo justificativo, al argumento interpretativo que fundamenta una atribución de significado por su concordancia con las intenciones de los autores de la Constitución, manifestadas en su historia fidedigna (la que se suele identificar, como se sabe, con las actas de la Comisión de Estudios de la Nueva Constitución). Esta práctica sugiere una comprensión de la función de la constitución que parece dominada por la imagen, propia del derecho privado, de un contrato en el que las partes asumen un acuerdo y dan solución a través de él a las cuestiones que los vinculan. De modo que si surgen controversias en el transcurso de esa relación por ejemplo, a algunos les parece inaceptable la aprobación de una ley que despenalice ciertas formas de aborto- resulta razonable esperar que un tribunal encuentre la solución en el contrato, interpretando sus disposiciones conforme a las intenciones expresadas en las negociaciones preliminares.

Es interesante notar que, como ha puesto de relieve Robert BURT, la misma metáfora del contrato parece subyacer al método de interpretación constitucional que en derecho comparado compite con el método del originalismo y que en lugar de requerit que se atienda a las intenciones del constituyente, exige al intérprete desarrollar la mejor concepción de los conceptos abstractos expresados en el documento constitucional, para determinar sus consecuencias en relación a las controversias especificas que necesiten solución. ${ }^{38}$ También en el caso de esta directiva hermenéutica, que parece predominar en las prácticas constitucionales europeas y que corresponde al método de la "lectura moral" de la Constitución defendido por DWORKIN, se trata a la constitución como si fuera un contrato; la diferencia consiste en que para determinar las soluciones que de él resultan a los problemas que vinculan a las partes se confía más en el desarrollo coherente de los principios originalmente suscritos que en las intenciones manifestadas durante la negociación.

16. El segundo aspecto de nuestra práctica constitucional que exhibe singular constancia y estabilidad es la interpretación de los derechos fundamentales como derechos directamente aplicables entre particulares, unida a la interpretación amplia de las facultades que confiere el recurso de protección para obtener tutela jurisdiccional frente a la amenaza por una particular del derecho de otro particular. ${ }^{39}$

Esta interpretación de las disposiciones sobre derechos fundamentales, que determina en nuestra práctica jurídica un grado de constitucionalización que no encuentra equivalente en otros sistemas jurídicos, ${ }^{40}$ presupone una peculiar concepción del Estado de Derecho. Una concepción en la que el imperio del derecho no es entendido como la sujeción a las reglas generales establecidas por la ley, a la que le corresponde determinar el punto en que la libertad de uno lesiona la libertad del otro, sino como la sujeción a las disposiciones particulares y concretas a través de las cuales los jueces determinan el alcance de nuestros derechos. Bajo esa concepción del Estado de derecho, por otra parte, a los tribunales no sólo les corresponde hacer efectiva la responsabilidad de los ciudadanos por las infracciones a los límites legales de sus libertades, sino también preveriir su posible mal uso. De manera muy expresiva Eduardo ALDUNATE ha presentado esta concepción del Estado de derecho como la de un "Estado Policíaco Judicial".,41

\footnotetext{
${ }^{38}$ Cfr. BURT, R “Metodología y Metáfora en el Derecho Constitucional”, en Isonomía, Nº 6 ,abril, 1997 , pp. 31 y 32.

${ }^{39}$ Sobre eilas cfr., por ejemplo, ALDUNATE, E., "El Efecto de Irradiación de los Derechos Fundamentales", En: J. C. FERRADA (editor.), op. cit.. (nota 32) y JANA, A. "La Eficacia Horizontal de los Derechos Fundamentales", En: AAVV, Los Derechos Fundamentales, Buenos Aires, Editores del Puerto, 2003.

40 Una clara explicación de sus diferencias con respecto a la concepción alemana y en general europea del efecto de irtadiación de los derechos fundamentales puede verse en ALDUNATE, E., op. cit.. (nota 39).

${ }^{41}$ ALDUNATE, E., op. cit. (nota 37), p. 241.
} 


\section{Dos tesis de teoría normativa de la interpretación constitucional}

17. A pesar de mis esfuerzos de neutralidad, posiblemente el lector habrá presagiado mi aproximación crítica a los rasgos de nuestra práctica constitucional que antes he descrito. Lo que haré en esta sección es delinear someramente esa crítica, presentando una concepción de la función de la constitución y una concepción del Estado de derecho que se contraponen a las que parecen subyacer a nuestra práctica y en las que puede apoyarse una forma diferente de afrontar el juego de la interpretación constitucional. Al hacerlo voy a dar por supuestas, y no voy a someter a discusión, las condiciones estructurales que han conformado nuestra práctica de interpretación constitucional, esto es, la previsión de una determinada forma de garantía jurisdiccional de la constitución.

18. Ciertamente la asunción de la metáfora de la constitución como un contrato -y sobre todo su versión ligada a una metodología de interpretación originalista- está sujeta a objeciones especiales en el caso de una constitución como la chilena de 1980. Sin embargo, el punto que quisiera discutir afecta en general el valor de esa metáfora y abarca también su segunda versión, ligada a la metodología de la lectura moral de la constitución. Básicamente, creo que pretender que a través de la constitución una comunidad política acuerda las soluciones a las cuestiones que la vinculan supone atribuirle una función inadecuada, porque resulta incompatible con la naturaleza de esas cuestiones: pues el problema que enfrentan las sociedades modernas al constituirse jurídicamente es precisamente el de la necesidad de coordinar las acciones e interacciones de sus miembros no obstante el desacuerdo sustantivo en torno al modo en que esas acciones e interacciones debieran ser reguladas. ${ }^{42}$ Es esa inadecuación de fondo la que reaparece cuando se consideran los obstáculos que tienen que encarar los dos métodos de interpretación constitucional asociados a la metáfora del contrato: las dificultades de identificación de intenciones a la vez comunes y de detalle en el caso del método originalista y las dificultades asociadas al carácter esencialmente controvertido de los conceptos constitucionales en el caso del método de la lectura moral. ${ }^{43}$

Una metáfora que me parece más fecunda desde el punto de vista normativo es la que propone R. BURT, en reemplazo de la del contrato entre privados, y que sugiere concebir a la constitución como si se tratara de un tratado celebrado entre naciones independientes previamente en conflicto para poner fin o evitar una guerra. ${ }^{44}$ La función que esta analogía supone atribuir a la constitución es la de una promesa de no recurrir a la guerra civil, que fija las condiciones que sustentan la posibilidad de convivencia pacífica, en la que podamos reconocernos como comunidad y respetarnos como adversarios políticos.

Esta concepción de la función de la constitución no pretende que a través de ella hayamos resuelto nuestras disputas sustantivas y destaca la centralidad de las normas constitucionales que institucionalizan el procedimiento democrático de decisión política, dando una respuesta aceptable a la necesidad de coordinación en un contexto de controversia. Pero, ¿qué sentido pueden tener a la luz de esta función las normas constitucionales que declaran derechos fundamentales y cómo debiera ser su interpretación con vistas a la revisión de la constitucionalidad de las leyes? (Es importante recordar que

\footnotetext{
${ }^{42}$ Sobre la relevancia de esta citcunstancia para la teoría jurídica y en particular para la teoría constitucional vid. WALDRON, J. Law and Disagreement. Oxford, Oxford U. Press, 1999 y ATRIA, F. "La Constitución y la Contingencia de lo Político", en Doxa. $N^{\circ}$ 26, 2003 y Derecho y Humanidades, Facultad de Derecho, Universidad de Chile, No 11,2005 , pp. 19-39. .

${ }^{43}$ Sobre las primeras vid., por ejemplo, DWORKIN, R., Life's Dominion. Nueva York, Alfred A. Knopf, 1993, pp. 119 y ss. Sobre las segundas vid. WALDRON, J. "Vagueness in Law and Language: Some Phijosophical Issues", en Califomia Law Review, $\mathrm{N}^{\circ} 82,1994$. Hay circunstancias en que estos obstáculos pueden ser salvados --si efectivamente hubiera intenciones de los constituyentes que son a la vez comunes y de detalle y si la constitución asume una cierta concepción que fije el contenido de un concepto controvertido, respectivamente- pero entonces, bajo esas circunstancias, los métodos interpretativos en cuestión suscitarán objeciones políticas que replicarán el argumento de la inadecuación normativa de la concepción de la constitución como un contrato.

${ }^{4}$ BURT, R. op. cit.. (nota 38), pp. 33 y ss.
} 
en esta parte del trabajo se ha partido del supuesto de una constitución que prevé algún mecanismo de garantía jurisdiccional y que suscita, por consiguiente, la pregunta por las directivas que debiera guiar su interpretación operativa.)

Las disposiciones constitucionales que consagran derechos fundamentales constituyen, en el marco de esa concepción de la constitución, las condiciones de la convivencia pacífica que la comunidad se fija. La cuestión consiste en cómo concebir esa calidad de condiciones de modo que no volvamos, por otta vía, a pretender que ellas puedan dar solución a nuestros desacuerdos sustantivos. En mi opinión, WALDRON apunta en la ditección correcta cuando atribuye a los conceptos a través de los cuales se expresan las normas sobre derechos fundamentales el papel de garantizar que en la sociedad tengan lugar determinados debates, de modo que, por ejemplo, no puedan disponerse penas sin discutir si son o no "crueles". 45 Esta forma de entender el sentido de las normas sobre derechos fundamentales puede conectarse, a mi juicio, con una concepción del control judicial de constitucionalidad de la ley que tesulta próxima a la idea de una "policía dialógica" defendida por B. ACKERMAN y en la que se trata de velar por que el legislador democrático se haya situado efectivamente en la arena verbal que instituyen los conceptos constitucionales, haciéndose las preguntas que ellos abren. ${ }^{46} \mathrm{El}$ espacio más significativo en el que puede tener lugar ese control de omisiones en la deliberación, es el de las condiciones de legitimidad de limitaciones a algún derecho constitucionalmente protegido. ${ }^{47} \mathrm{Al}$ margen de ese espacio, la teoría normativa de la interpretación constitucional que se apoye en la red de concepciones de la constitución, de las normas iusfundamentales y del control de constitucionalidad que han sido delineadas, debiera incluir una directiva fuerte de deferencia al legislador democrático, reconociendo que esa es la sede propia de discusión y decisión entre concepciones políticas rivales.

19. La concepción antes delineada de la constitución resulta fácilmente asociable con una concepción del Estado de derecho que reconozca la dignidad de la legislación y le atribuya a la ley el papel de trazar, de modo general y ex-ante, el límite en el que la libertad de ciudadano cede frente a los derechos de otro. Por consiguiente, ella sienta también las bases para una crítica de la concepción del imperio del derecho que subyace a la interpretación del efecto horizontal de los derechos fundamentales que domina en nuestra práctica constitucional. ${ }^{48}$

Esa concepción alternativa, que no es sino una vuelta a la concepción clásica del Estado de derecho, requeritría un drástico redimensionamiento en la interpretación del ámbito de aplicación del recurso de protección y aconsejaría una interpretación del efecto horizontal que no vaya más allá del efecto mediato o indirecto, que no sustituye a la ley sino que la complementa en los espacios que ella misma ha abierto a la deliberación - -a través de referencias como la que el artículo $10 \mathrm{n}^{\circ} 10$ del Código Penal hace al "ejercicio legítimo de un derecho"- o permite su interpretación restrictiva cuando el

45 WALDRON, J. op. cit.. (nota 43), p. 540. Así explica WALDRON que tenga sentido un acuerdo que no disuelve nuestros desacuerdos: "En nuestra sociedad no estamos de acuerdo en muchas cosas, pero tal vez podemos concordat en esto: somos una sociedad mejor por seguir discutiendo acerca de determinadas cuestiones de lo que seriamos si esas discusiones se concluyetan artificial o estipulativamente"

46 ACKERMAN, B. Social Justice in the Liberal State, New Haven, Yale U. Press, 1980, pp. 310-312.

47 Existe en nuestra jurisprudencia reciente un caso que da muestras de una acertada tarea interpretativa en este sentido. Se trata de la sentencia del Tribunal Constitucional relativa al proyecto de la ley que creó la Unidad de Análisis Financiero (19.913), que declaró inconstitucional el proyecto de disposición legal que imponía a toda persona la obligación de proporcionar gratuitamente al nuevo organismo todos los antecedentes que le solicitara, aun tratándose de antecedentes amparados en secreto o reserva (excepto aquellos amparados por secreto profesional). La fundamentación de la decisión se centra en el análisis de las condiciones de legitimidad de la restricción del derecho de privacidad que dicha exigencia implicaba, considerando, en particulat, la inexistencia de limitaciones sustanciales clatas y la insuficiencia de las gatantías procesales previstas (autorización del Presidente de la Corte de Apelaciones de Santiago, sin audiencia del afectado) tratándose de informaciones bajo reserva o secreto. Vid. al respecto el comentario de CORREA, Rodrigo P., "Tribunal Constitucional", en Revista de Derecho de la U. Adolfo Ibáñez, No 1, 2003, pp. 524 y ss.

${ }^{48}$ Se trata de una tesis normativa compartida por ALDUNATE, E., op. sit. (nota 39), pp. 31 y ss. y por CORREA, R. P., "Derechos Constitucionales", en Revista de Derecho de la U. Adolfo Ibáñez, N N 12003 , pp. 564 -565. 
caso en cuestión presenta, a la luz de los conceptos constitucionales, una dimensión que el legislador no parece haber considerado.

Para concluir: las responsabilidades de la teoría

20. En su intervención en este mismo Congreso Carlos Peña se refería a la relevancia de las discusiones teóricas en la configuración de una cultura política. Ese es precisamente el sentido que en mi opinión tienen también las discusiones teóricas sobre la interpretación constitucional. Su relevancia práctica es notable si pensamos que un cambio en la cultura política que inspira nuestras prácticas de interpretación constitucional puede significar un cambio progresivo de nuestras prácticas constitucionales.

Espero entonces que podamos convenir a estas alturas en que vale la pena que sigamos encontrándonos en congresos (no sólo de Derecho sino también) de Teoría Constitucional. 